\title{
Isolation and characterization of Mycobacterium bovis strains from indigenous Zambian cattle using Spacer oligonucleotide typing technique
}

\author{
Musso Munyeme*1, Leen Rigouts ${ }^{2}$, Isdore Chola Shamputa ${ }^{2,6}$, \\ John Bwalya Muma ${ }^{1}$, Morten Tryland ${ }^{3}$, Eystein Skjerve ${ }^{4}$ and Berit Djønne ${ }^{5}$
}

Address: ${ }^{1}$ Department of Disease Control, University of Zambia, School of Veterinary Medicine, PO Box 32379 Lusaka, Zambia, ${ }^{2}$ Mycobacteriology Unit, Prince Leopold Institute of Tropical Medicine, 155 National Straat, 200 Antwerp, Belgium, ${ }^{3}$ Department of Food Safety and Infection Biology, Section of Arctic Veterinary Medicine, Norwegian School of Veterinary Science, Stakkevollveien 23, N-9010 Tromsø, Norway, ${ }^{4}$ Department of Food Safety and Infection Biology, Norwegian School of Veterinary Science, PO Box 8146 Dep, 0033 Oslo, Norway, ${ }^{5}$ Department of Animal Health, National Veterinary Institute, PO Box 750 Dep, 0033 Oslo, Norway and ${ }^{6}$ Tuberculosis Research Section, National Institutes of Health, LCID/NIAID, Bethesda, MD 20892, USA

Email: Musso Munyeme* - munyeme@yahoo.co.uk; Leen Rigouts - LRigouts@itg.be; Isdore Chola Shamputa - shamputai@niaid.nih.gov; John Bwalya Muma - jbwalya@lycos.com; Morten Tryland - morten.tryland@veths.no; Eystein Skjerve - eystein.skjerve@veths.no; Berit Djønne - berit.djonne@vetinst.no

* Corresponding author

Published: 20 July 2009

BMC Microbiology 2009, 9:144 doi:10.1|86/|47|-2/80-9-144
Received: 8 April 2009

Accepted: 20 July 2009

This article is available from: http://www.biomedcentral.com//47I-2/80/9//44

(c) 2009 Munyeme et al; licensee BioMed Central Ltd.

This is an Open Access article distributed under the terms of the Creative Commons Attribution License (http://creativecommons.org/licenses/by/2.0), which permits unrestricted use, distribution, and reproduction in any medium, provided the original work is properly cited.

\begin{abstract}
Background: Bovine tuberculosis (BTB), caused by Mycobacterium bovis, has remained a major source of concern to public health officials in Zambia. Previous investigations have used traditional epidemiological methods that are unable to identify the causative agent and from which dynamics of disease dispersion is difficult to discern. The objective of this study was to isolate, characterize and determine the genetic diversity and relatedness of $M$. bovis from major cattle rearing districts in Zambia by spoligotyping. A total of 695 carcasses were examined and 98 tissues had gross postmortem lesions compatible with BTB.

Results: Forty-two out of the ninety-eight suspected tissues examined had culture properties characteristic of mycobacteria from which $3 \mathrm{I}$ isolates yielded interpretable spoligotypes. This technique showed good discriminatory power $(\mathrm{HGDI}=0.98)$, revealing 10 different spoligotype patterns. Twenty-seven isolates belonged to one cluster with more than $95 \%$ similarity and inside the cluster, one predominant spoligotype was found in $20(64.5 \%)$ of the isolates tested. The highest number of spoligotypes was observed among samples from Namwala district. Spoligotypes from $26(83.9 \%)$ of the isolates belonged to five spoligotypes that have been reported before while the remaining 5 ( $16.1 \%)$ isolates had unique spoligotypes that are being reported for the first time; these have been assigned numbers SBI763 to SBI767. Five of the 6 districts had the predominant spoligotype (SBOI20).

Conclusion: The study has described the dispersion patterns of $M$. bovis in Zambian cattle for the first time and has identified 5 spoligotype patterns specific to Zambia. The observation of an overlap in the spoligotype pattern SBOI 20 in 5 of the 6 districts suggests the probability of sharing a common source of infection.
\end{abstract}




\section{Background}

Bovine tuberculosis (BTB), caused by Mycobacterium bovis, has been reported to be endemic in the Zambian traditional livestock sector [1-3], with relatively high prevalence being recorded in areas within and adjacent the Kafue Basin $[1,4,5]$. Prevalence rates at individual animal level vary from $0.8 \%$ in low prevalence settings to $9.6 \%$ in high prevalence settings, whilst herd level prevalence vary from $5.6 \%$ in low prevalence settings to $49.8 \%$ in high prevalence settings $[3,4]$. Recent survey data suggest that areas of high prevalence settings exist within the country [3]. One such area being the Kafue Basin of Zambia, were the livestock/wildlife interface forms a unique risk platform in terms of spread of infectious diseases among animals (both domestic and wild) [4-6].

BTB is one of the most common abattoir findings during meat inspection and a significant reason for organ condemnation $[7,8]$. The lack of abattoirs in most districts, coupled with the high cost of mechanized transport, entails cattle travelling long distances "on the hoof", sometimes passing through two or more districts before reaching the abattoirs. This kind of animal movement has been identified as the major hindrance in the control of most economically important diseases of livestock in Zambia [9]. Similarly, strains of Mycobacterium bovis may be spread across districts due to these uncontrolled animal movements. However, there is no information with regards to the molecular epidemiology of BTB in Zambia.

Molecular typing techniques have contributed greatly to the knowledge of inter-bovine and interspecies transmission of bovine tuberculosis [10-13]. The most widely used DNA typing techniques for M. bovis include IS6110 in restriction fragment length polymorphism (RFLP) typing [14], spacer oligonucleotide typing (Spoligotyping) [15] and variable number of tandem repeat (VNTR) typing [14-16]. RFLP is less desirable because it requires large amounts of DNA, is not based on Polymerase Chain Reaction (PCR), is time consuming, and poorly resolve strains of $M$. bovis owing to low copy numbers of IS6110 elements [17]. Both VNTR and Spoligotyping are PCR based, easy to perform, require little amounts of DNA, and can be used even with non-viable organisms. Spoligotyping has been more widely applied in part because it is fast and more importantly the technique can simultaneously detect and differentiate $M$. bovis from $M$. tuberculosis strains $[15,16,18,19]$. In addition, Spoligotyping patterns can be easily compared with results from other countries by use of a freely accessible international data base [20].

The objective of this study was to determine the genetic diversity and relatedness of ВТВ isolates from cattle in Zambia.

\section{Results}

Out of the 695 carcasses examined, 98 (14.1\%) tissues and organs from the carcasses had gross characteristic lesions suggestive of tuberculous lesions. When subjected to culture on pyruvate enriched Lowenstein Jensen media, only $42(6 \%)$ of the tissues resulted in discernable colony growth with properties suggestive of mycobacteria but only $33(4.7 \%)$ samples were acid-fast positive by smear microscopy. Out of this number, 31 isolates yielded interpretable spoligotypes of $M$. bovis with all the six major districts around the Kafue Basin contributing at least one isolate each; Namwala $(n=12)$, Lusaka $(n=6)$, Mumbwa $(n=5)$, Monze $(n=5)$, Mazabuka $(n=2)$, Choma $(n=1)$ (Figure 1 and Table 1). All isolates lacked the spacers 3, 9, 16 and also from 39 to 43 , a characteristic feature that distinguishes M. bovis from M. tuberculosis [15].

Ten different spoligotypes were distinguished (Table 1 and Figure 2). Twenty-seven isolates belonged to one cluster with more than $95 \%$ similarity (Figure 2); they all have spacers $2,4-8,11-14,17-23$ and 25-37. Inside the cluster, one predominant spoligotype was found in 20 $(64.5 \%)$ of the isolates tested. It was found in animals originating from 5 of the 6 study districts. The second most prevalent spoligotype was found in isolates from three districts; C4 from Namwala, C13 from Choma and C15 from Mumbwa (Table 1 and Figure 2). Three isolates in the cluster, C16 and C42 from Namwala and C14 from Lusaka are closely related to each other with only spacer 1 , 24 and 38 being different (Figure 2).

Four isolates, C21, C26, C9 and C19, showed a low degree of similarity with the other 27 isolates. Isolate C9 from Monze district and C19 from Namwala are clearly distinct from the rest; $\mathrm{C} 19$ is lacking all the spacers from 1 to 24 (Figure 2).

In terms of geographic variability, Namwala district had a total of 7 spoligotypes of which 5 isolates (C19, C26, C42, $\mathrm{C} 16$ and C41) were only present in the Namwala district (Table 1).

Based on the global spoligotype patterns diversity provided by the international data base on spoligotyping, http://www.mbovis.org, $83.9 \%$ of the isolates have spoligo patterns that have been described in other countries (Table 2). The predominant spoligotype, widely dispersed geographically (Table $1 \& 2$ ), was found in the international data base to have a pattern with a spoligotype number SB0120 with the corresponding hexacode of 6F5F-5F-7F-FF-60. Five out of the six study districts had this predominant spoligotype, and Namwala district accounted for $30 \%$ of spoligotype SB0120. The second most predominant spoligotype had a pattern named 


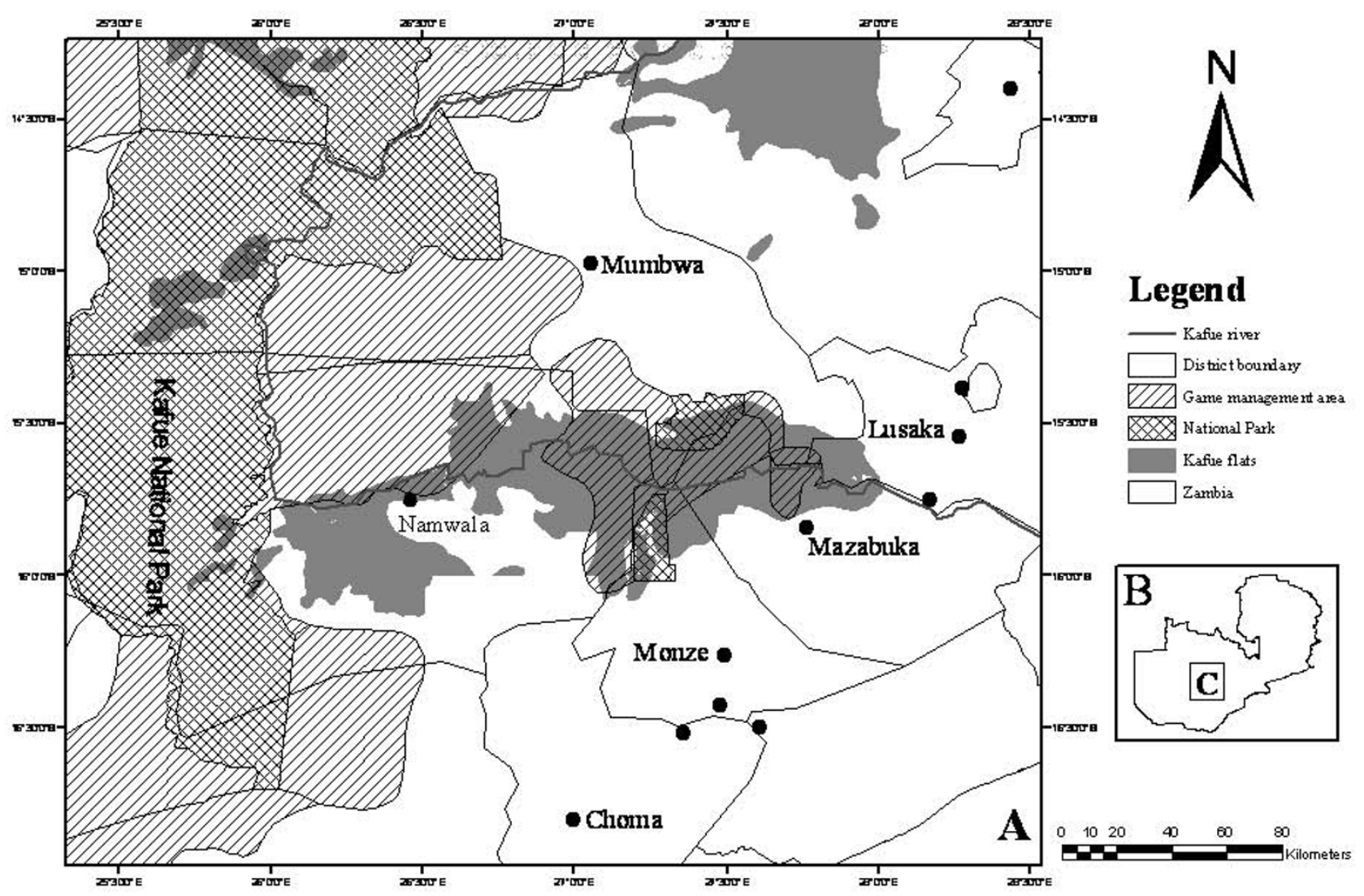

Figure I

Map of the Kafue Basin. A - indicates major districts. B - insert of map of Zambia. C - study area.

SB0871 with a corresponding hexacode of 6F-4F-5F-7FFF-60. Isolates C14 was named SB1572 with a hexacode number of $6 \mathrm{~F}-5 \mathrm{~F}-5 \mathrm{~F}-7 \mathrm{~F}-\mathrm{FF}-40$, isolate C16 was SB1536 with a hexacode number of 2F-5F-5F-6F-FF- 60 and isolate C19 was SB0162 with a hexacode number of 00-00-00-0FFF-60. The distribution of these spoligotypes on the international data base is shown in Table 2.

Five individually occurring isolates (16.1\%) displayed new spoligo patterns that have not yet been described on the international spoligotyping data base (Figure 2 and Table 2). These isolates originated from Namwala district (isolate C26, 42 and C41); from Mumbwa (isolate C21); and from Monze (isolate C9) (Table 1 and Figure 2). These new patterns were allotted new spoligo numbers as SB1763 (hex code 66-03-5F-6D-FF-60), SB1764 (hex code 60-0F-1F-6C-FF-00), SB1765 (hex code 2F-5F-5F-7F-FF40), SB1766 (hex code 6F-4F-1F-6F-FF-60) and SB1767 (hex code 62-0E-50-09-FF-40) by http://www.mbovis.org Table 2.

The technique showed a good discrimination power; Hunter Gaston Discriminatory Index (HGDI = 0.98) (Table 1 and Figure 2.).

\section{Discussion}

Our results do not agree with what has been found in other parts of Africa [21,22], where more than $40 \%$ of the animals with tuberculous lesions had Non-tuberculous Mycobacteria (NTM). In this study, only two animals had mycobacteria other than $M$. bovis. However, our findings tie up with a similar study conducted in Algeria [23]. Whereas excluding the differences in bacterial species as accounting for these observations [23], strain isolation has been found to be dependant on the specific type of media used [24]. The usage of specific culture media such as Stonebrink has been shown to increase the recovery and discrimination of strains on culture [25,26]. However, in this study, the use of Lowenstein Jensen media with pyruvate enrichment may to a lesser extent account for the low numbers of NTMs although not conclusively established. This study is the first of its kind in Zambia to describe the molecular typing of M.bovis isolates from indigenous cattle breeds originating from high prevalence settings.

Characterization of $M$. bovis strains based on different geographical locations by districts or region is pivotal in understanding the molecular epidemiology of BTB 
Table I: Distribution of spoligotypes of Mycobacterium bovis isolates from cattle in six different districts of Zambia in 2004

\begin{tabular}{|c|c|c|c|c|c|c|c|c|c|}
\hline \multirow{4}{*}{ Isolate } & \multicolumn{7}{|c|}{ DISTRIBUTION OF SPOLIGOTYPES PER DISTRICT } & \multirow{4}{*}{$\begin{array}{c}\text { Total } \\
\text { No. }\end{array}$} & \multirow{4}{*}{$\begin{array}{c}\text { Frequency } \\
\text { (\%) }\end{array}$} \\
\hline & Spoligotype & $\mathrm{L}$ & M & C & $M$ & M & $N$ & & \\
\hline & \multirow[t]{2}{*}{ SB Number* } & $\mathrm{S}$ & Z & $\mathrm{H}$ & B & Z & M & & \\
\hline & & $\mathrm{K}$ & $\mathrm{K}$ & M & W & $\mathrm{E}$ & A & & \\
\hline C9 & SB I 767 & & & & & 1 & & 1 & 3.2 \\
\hline $\mathrm{C} 19$ & SBOI 62 & & & & & & I & I & 3.2 \\
\hline $\mathrm{C} 21$ & SB I 763 & & & & 1 & & & 1 & 3.2 \\
\hline $\mathrm{C} 26$ & SB I 764 & & & & & & I & 1 & 3.2 \\
\hline $\mathrm{Cl} 4$ & SB I 572 & I & & & & & & 1 & 3.2 \\
\hline C42 & SB I 765 & & & & & & I & 1 & 3.2 \\
\hline $\mathrm{Cl} 6$ & SB I 536 & & & & & & I & 1 & 3.2 \\
\hline $\mathrm{C} 4, \mathrm{Cl} 3, \mathrm{Cl} 5$ & SB087I & & & 1 & 1 & & I & 3 & 9.7 \\
\hline C4I & SB I 766 & & & & & & 1 & 1 & 3.2 \\
\hline \multirow{2}{*}{\multicolumn{10}{|c|}{$\begin{array}{l}\mathrm{C} 2, \mathrm{C} 3, \mathrm{C} 5 \\
\mathrm{C} 6, \mathrm{C} 8, \mathrm{Cl}\end{array}$}} \\
\hline & & & & & & & & & \\
\hline \multicolumn{10}{|l|}{$\mathrm{C} 18, \mathrm{C} 22$} \\
\hline \multicolumn{10}{|l|}{ C24, C25, } \\
\hline C27, C28, & SBOI 20 & 5 & 2 & & 3 & 4 & 6 & 20 & 64.5 \\
\hline \multicolumn{10}{|l|}{ C29, C31, } \\
\hline \multicolumn{10}{|l|}{ C38, C39, } \\
\hline \multicolumn{10}{|l|}{$\mathrm{C} 40, \mathrm{C} 44$} \\
\hline \multicolumn{10}{|l|}{ C45, C46 } \\
\hline Total number & & 6 & 2 & I & 5 & 5 & 12 & 31 & \\
\hline
\end{tabular}

*Allocated by database http://www.mobovis.org/; C = Cattle strain Identification number.

Abbreviations used for districts $(n=3 I)$ : LSK = Lusaka; $M Z K=$ Mazabuka; $C H M=$ Choma; $M B W=$ Mumbwa; $M Z E=$ Monze; NMA = Namwala.

$[21,23,27]$. It further helps in understanding the dynamics of disease dispersion which are difficult to appreciate through traditional epidemiological investigative tools. However, through the use of modern molecular epidemiological tools such as spoligotyping, we have been able to demonstrate the presence as well as the specific existing strains of Mycobacterium bovis in Zambian cattle. The technique has shade more light on the strain diversity, distribution and relatedness within Zambia and globally. Two dominant spoligotypes were identified representing the majority of isolates analyzed. These findings intimate a degree of homogeneity among $M$. bovis isolates in Zambia. However, when distinguishing between unrelated strains through the application of the Hunter-Gaston Discriminatory Index $[28,29]$, the spoligotyping technique in this particular case was found to have a good discrimination power. The index indicated that $98 \%$ of the strains had an equal chance of having different spoligo patterns if randomly sampled.

Of the $31 \mathrm{M}$. bovis isolates that yielded interpretable spoligotypes, 10 different patterns were detected. Based on the global spoligotype patterns diversity provided by the international data base on spoligotyping, http:// www.mbovis.org, $83.9 \%$ of the isolates have been described. The predominant spoligotype that was widely dispersed geographically was found on the international data base to have a pattern with a spoligotype number SB0120. This spoligotype is similar to the spoligotype of the vaccine strain BCG type, and previously described in France, Belgium, South Africa, The Netherlands, Sri Lanka, Spain, Japan, Portugal, Russia, Iran, Denmark, China and Brazil http://www.mbovis.org[30]. The second most predominant spoligotype had a pattern previously numbered SB0871 and has been described from France. These predominant patterns, SB0120 and SB0871, differ only by a single spacer (spacer 10). The most common spoligotype, SB0120, has a considerable degree of geographical dispersion in Zambia, being detected in 5 out of the 6 districts, and has further been shown to be common in other countries including continental Europe [31,32]. This finding of strains from Europe may suggest the introduction of the disease by early European settlers to Africa, a finding that has been highlighted by different workers $[17,23,27]$. The finding of SB0120 in South Africa strongly infers to this probability, when tracing the early migration routes of colonial settlers to Zambia. In our current study, 16.1\% (5/31) of the isolates had spoligotypes that were unique to Zambia. These spoligotypes were newly described considering that no previous information of their registration on the international data base existed. These patterns (SB1763-1767) reveal deletion events that could have lead to new spoligotype patterns evolving, as was the case 


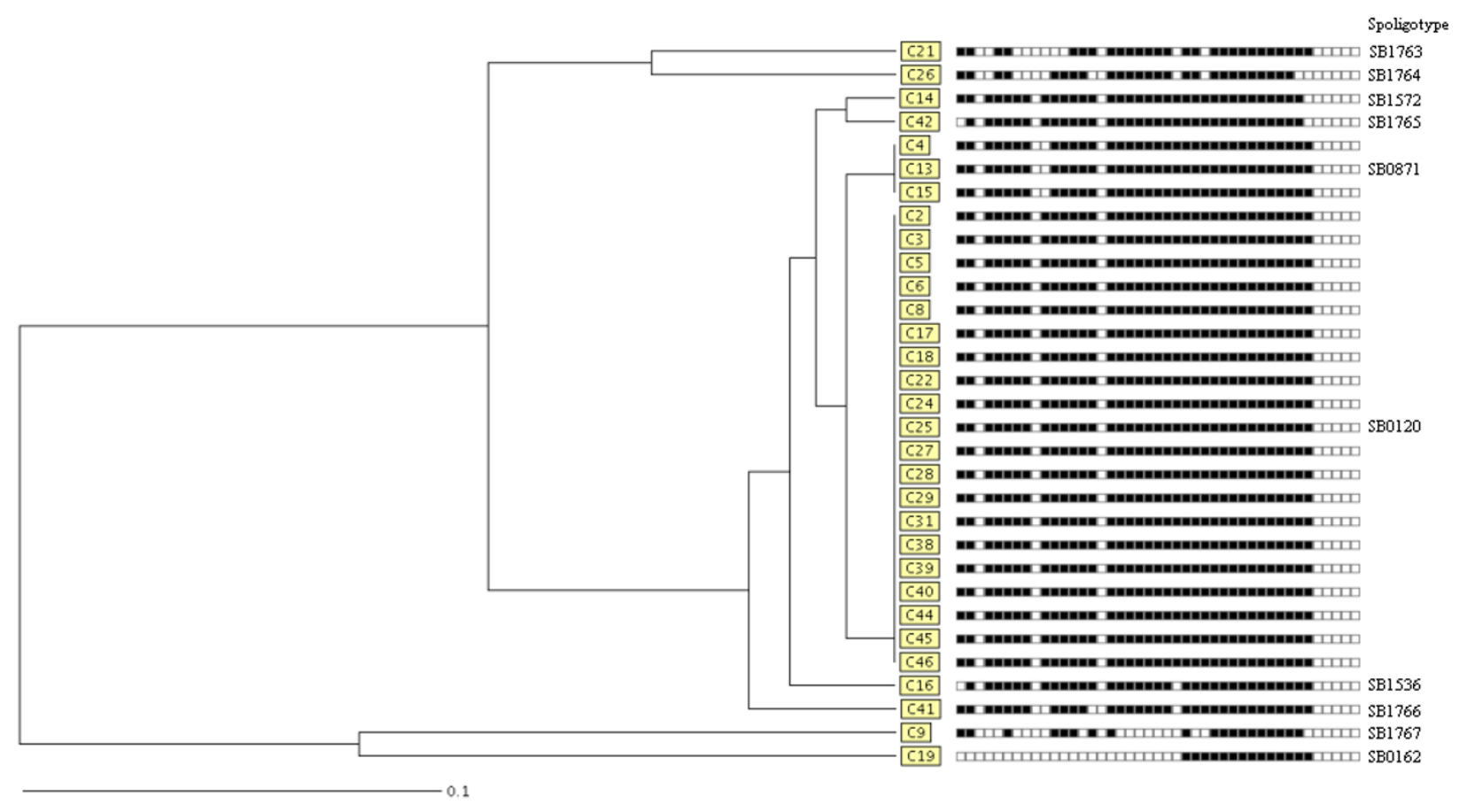

Figure 2

Relationship of spoligotypes of $\boldsymbol{M}$. bovis isolates from Zambian cattle. The presented patterns were generated using the band-based dice coefficient and clustering determined by the unweighted pair group algorithm with arithmetic averages (UPMGA) method. Designation of spacers from left to right is I to 43. Numbers on the right represent spoligotypes described in the international database http://www.mbovis.org.

in Portugal [30]. However, more detailed studies need to be conducted to fully ascertain this assertion.

The sharing of grazing land in the Kafue Basin in Zambia between cattle and Kafue lechwe antelopes (Kobus leche Kafuensis), considered as wildlife biological reservoir hosts for BTB, might explain the high prevalence levels found in this setting $[3,4,6,33]$. Underlying factors in sus- taining the infectious agent depend on the temporal and spatial distribution between the source of infection and the susceptible animals, which also are a function of the duration of interaction between the agent, the susceptible host and its environment [34]. The underlying factors for BTB transmission between the Lechwe antelopes and cattle are reported to be optimal in the Kafue Basin $[3,6]$,

Table 2: Major Spoligotypes in Zambia

\begin{tabular}{llc}
\hline Spoligotype & Shared type & Geographical distribution \\
\hline SpI & SB0120 & France, Belgium, Brazil, South Africa, Sri Lanka, Iran, The Netherlands, Spain, China, Japan, Portugal, Russia, Denmark, \\
& & Zambia \\
Sp2 & SB087I & France \\
Sp3 & SBI763* & Zambia \\
Sp4 & SBI764* & Zambia \\
Sp5 & SBI572 & Italy \\
Sp6 & SBI765* & Zambia \\
Sp7 & SBI536 & Italy \\
Sp8 & SBI766* & Zambia \\
Sp9 & SBI767* & Zambia \\
Spl0 & SB0162 & Belgium \\
\hline
\end{tabular}

I Arbitrary spoligotype designation

2 Shared type, designation of the spoligotype in the World Spoligotype Database.

*New Spoligotype assigned by http://www.mbovis.org 
although further investigations at molecular level will be necessary to elucidate this relationship.

The tracing of livestock movement patterns from their areas of origin to major abattoirs is important in understanding possible disease dispersion patterns. Cattle traders trek for days from areas within and around the Kafue Basin to abattoirs in the nearby districts[3]. In our study, we observed that identical and closely related strains were also found in other districts. These findings suggest the sharing of strains between districts, a finding which is important when determining BTB localization or spread.

Namwala district (the only district right in the Kafue Basin) [8] was found to have more isolates than any other district. The practice of allowing trekking animals to spend one or more nights in different kraals during the journey to abattoirs may partially be responsible for the dissemination of the infectious organisms. This pattern of animal movements may to a greater extent be responsible to the observed dispersion of spoligotype patterns suggestively, based on our results from the Namwala district zones to other surrounding districts. However, these results need to be interpreted with caution considering limitations related to the survey period and sample size related to limited resources and time constraints. This makes the results a bit difficult to interpret when inferring to the entire region given the representativeness of the sample size. In addition, the spoligotyping technique has weaknesses in that it has a low discriminatory power [29] which may result in low specificity of some patterns with a possibility of grouping strains that might not be identical when typed by other methods. However, the results obtained in this study give an indication of $M$. bovis strains in cattle with an insight in the likely role that cattle movements have on the dissemination of the disease.

These findings are useful in assisting policy makers when considering the formulation of control measures for BTB in Zambian cattle. It is important for policy makers to base their control polices on researched scientific evidence. This study has highlighted that unrestricted cattle movements to abattoirs may play a major contributory role in the dissemination of BTB. Thus policy makers should consider building abattoirs in all areas of high cattle production and further formulate a policy that will stop cattle movements "on the hoof" which will compel cattle owners to use trucks when transporting animals to abattoirs.

\section{Conclusion}

This study has described spoligotypes of M.bovis in Zambian cattle for the first time, and has identified five spoligotypes that are specific to the country. The observation of an overlap in the spoligotype pattern SB0120 in 5 of the 6 districts suggests a possible common source of infection.

\section{Methods}

\section{Specimen source areas}

The southern parts of Zambia are endowed with flood plains, which have suitable grazing grounds for both wild and domesticated animals. One such flood plain is the Kafue Basin which is surrounded by seven major districts (like counties) with a lot of sub districts/small towns within the major ones, supplying cattle to the main abattoirs in Lusaka, the capital city (Figure 1). More than over two-thirds of the Zambian cattle population which number about 2,500,000 animals are found in the southern region [8] with the traditional livestock sector accounting for more than $80 \%$ of the national population. The traditional sector consists of four distinct indigenous cattle breeds; the Agoni, a shorthorn Zebu (Bos indicus) breed from eastern Zambia; Tonga and Baila, Sanga breeds (cross breeds of Bos indicus and Bos taurus) from southern Zambia and the Barotse cattle, a Sanga breed from western Zambia. Based on epidemiological studies conducted on BTB in cattle [1,4], animals from the southern region were followed along the slaughter line and screened for any visible tuberculous lesions from March to June 2004.

\section{Sampling}

Slaughtered animals were followed along the examination line and examined for gross lesions according to the standard post mortem examination procedures by [35]. Organs and tissues with suspected TB lesions were collected after detailed postmortem examination of the entire carcass. Demographic data of area of origin, sex, age type of organ or tissue was recorded as well as the type of gross pathological postmortem disposition. These specimens were placed in sterile self zipping histopathological bags, placed into a cooler box with ice packs before transport to the laboratories where they were stored in a standard fridge (within four days) during processing for culturing or kept at $-20^{\circ} \mathrm{C}$ if not processed within four days.

\section{Decontamination and Culturing}

All the BTB suspect tissues and organs were decontaminated in the Biohazard Safety Cabinet in a Bio-safety Level 2 laboratory. Fat was trimmed off from the suspect material of which some 3 to $6 \mathrm{~g}$ was measured in a sterile mortar to which $10 \mathrm{ml}$ of $4 \%$ sodium hydroxide was added. An equal amount of sterile sand was added to the contents in the mortar and ground. The products were then transferred to McCartney bottles and centrifuged at low speed of $3000 \mathrm{rpm}$ for 10 minutes. Thereafter, the supernatant fluid was decanted off and $20 \mathrm{mls}$ of sterile water was added to the sediment and mixed vigorously by vortexing to a uniform homogenate. The contents were again centrifuged at low speed of $3000 \mathrm{rpm}$ for 20 minutes and the supernatant fluid was decanted. The sediments of these decontaminated homogenates were inoculated in dupli- 
cate Lowenstein-Jensen media slants supplemented with $0.4 \%$ sodium pyruvate to enhance the isolation of $M$. bovis and incubated aerobically at $37^{\circ} \mathrm{C}$ for 8 weeks. The resulting cultures were tentatively identified as probable $\mathrm{Myco-}$ bacterium tuberculosis-complex by their slow growth and colony morphology. Purity and acid-fastness of the colonies were checked by Zhiel Neelsen staining.

\section{Preparation of lysates and molecular typing of isolates}

Cell lysates were prepared by suspending a loop full of bacterial colony in $250 \mu$ l of $1 \times$ TE buffer ( $10 \mathrm{mM}$ Tris/ $\mathrm{HCl}, \mathrm{pH} 8.0$ and $1 \mathrm{mM}$ EDTA in distilled water) in an Eppendorf tube. Bacterial cells were heat killed by incubation at $80^{\circ} \mathrm{C}$ for 1 hour in a temperature controlled water bath. After centrifuging the cells at $13000 \mathrm{rpm}$ for $2 \mathrm{~min}-$ utes, the supernatant was discarded and the pellet resuspended in $500 \mu \mathrm{l}$ of $150 \mathrm{mM}$ sodium chloride. This step was repeated twice. Finally, the supernatant was discarded and the pellet resuspended in $25 \mu \mathrm{l} 1 \times$ TE buffer. These suspensions were used for spoligotyping as previously described [15]. Four microliters $(4 \mu \mathrm{l})$ of the denatured bacterial suspension from each sample was used for amplification of the direct-repeat (DR) region. The labelled amplicons were used as probes for hybridization with a set of 43 known oligonucleotide spacer sequences. The H37Rv M. tuberculosis, and M. bovis BCG P3 strains, and purified water were included in each experiment as positive and negative controls, respectively. Bound PCR fragments were detected with a streptavidinhorseradish peroxidase-enhanced conjugate and an enhanced chemiluminescence (ECL) system, followed by exposure to ECL hyperfilms (Amersham Pharmacia-Biotech, Roosendael, The Netherlands). The expected patterns of the positive controls were observed and no reagent contamination was detected in all the negative controls. The spoligotypes were compared using the band-based Dice coefficient and clustering determined by the unweighted pair group algorithm with arithmetic averages (UPMGA) method, using the MIRU-VNTR plus software[36]

\section{Calculating the Discriminatory power}

Hunter-Gaston Discriminatory Index (HGDI) equation was used for the calculation of the discriminatory power for the set of strains that were used in this study $[28,29]$. The equation used read as follows:

$$
D=1-\frac{1}{N(N-1)} \sum_{j=1}^{s} n j(n j-1)
$$

Where $D$ is the Index of discriminatory power, $s$ is the total number of the types to be described $n j$ is the number of strains in the population which are indistinguishable from the $j^{\text {th }}$ strain, and $N$ is the total number of strains in the sample population. The discriminatory power was cal- culated based on the consideration of an isolate per particular spoligotype in the study using the above formula derived from elementary probability theory.

\section{Authors' contributions}

MM contributed to the design, data collection, laboratory experiments, and analysis of data and drafting of the manuscript. LR contributed to the design, supervision of molecular typing, drafting and writing of manuscript. ICS contributed to carrying out molecular genetic studies, supervision of the work, drafting and reviewing of the manuscript. JBM contributed to the collection of field data in and drafting of the manuscript. MT contributed to supervision of the project, acquisition of parts of the funds and writing of the manuscript. ES contributed to the writing of manuscript. BD contributed to conception and design, data analysis and the writing of manuscript. All authors have read and approved the final manuscript.

\section{Acknowledgements}

The authors express their sincere gratitude for financial support from the Norwegian Programme for Development, Research and Education (NUFU). The technical support by School of Veterinary Medicine, Microbiology Laboratories, Chest Diseases Laboratories (CDL), under the Center for Disease Control (CDC), Lusaka Zambia and the Institute of Tropical Medicine (ITM), Antwerp, Belgium are all highly appreciated. Special thanks to Dr. Charles Maseka (Provincial Veterinary Officer, Southern Province) H. M. Chimana (UNZA) and Charles Sikende the field Veterinary Assistant.

\section{References}

I. Cook AJ, Tuchili LM, Buve A, Foster SD, Godfrey-Fausett P, Pandey GS, McAdam KP: Human and bovine tuberculosis in the Monze District of Zambia-a cross-sectional study. Br Vet J 1996, I 52(I):37-46.

2. Cosivi O, Grange JM, Daborn CJ, Raviglione MC, Fujikura T, Cousins D, Robinson RA, Huchzermeyer HF, de Kantor I, Meslin FX: Zoonotic tuberculosis due to Mycobacterium bovis in developing countries. Emerg Infect Dis 1998, 4(I):59-70.

3. Munyeme M, Muma JB, Skjerve E, Nambota AM, Phiri IG, Samui KL, Dorny P, Tryland M: Risk factors associated with bovine tuberculosis in traditional cattle of the livestock/wildlife interface areas in the Kafue basin of Zambia. Prev Vet Med 2008, 85(34):317-328.

4. Munyeme M, Muma JB, Samui KL, Skjerve E, Nambota AM, Phiri IG, Rigouts L, Tryland M: Prevalence of bovine tuberculosis and animal level risk factors for indigenous cattle under different grazing strategies in the livestock/wildlife interface areas of Zambia. Trop Anim Health Prod 2009, 4 I (3):345-352.

5. Sitima AC: Variability of Mycobacterium bovis in traditionally processed sour milk and the prevalence of bovine tuberculosis in Namwala district of Zambia. In MSc Thesis Lusaka: University of Zambia; 1997.

6. Pandey GS: Studies of the infectious diseases of the Kafue lechwe (Kobus leche kafuensis) with particular reference to tuberculosis in Zambia. Tokyo: Azabu University; 1998.

7. Anon: Annual report of the department of research and specialist services. Edited by: DRSS. Lusaka: Governement printers; 2000:45.

8. Anon: Annual report of the Department of Veterinary Services and Livestock Development. Edited by: Printers G. Lusaka: Government of the Republic of Zambia; 2004.

9. Pegram RG, James AD, Oosterwijk GP, Killorn KJ, Lemche J, Ghirotti M, Tekle Z, Chizyuka HG, Mwase ET, Chizyuka F: Studies on the economics of ticks in Zambia. Exp Appl Acarol 1991, I2(I2):9-26. 
10. Durr PA, Hewinson RG, Clifton-Hadley RS: Molecular epidemiology of bovine tuberculosis. I. Mycobacterium bovis genotyping. Rev Sci Tech 2000, 19(3):675-688.

II. Kazawala RR, Daborn CJ, Sharp JM, Kambarage DM, Jiwa SF, Mbembati NA: Isolation of Mycobacterium bovis from human cases of cervical adenitis in Tanzania: a cause of concern? Int J Tuberc Lung Dis 200I, 5(I):87-9I.

12. Kazwala RR, Kusiluka LJ, Sinclair K, Sharp JM, C JD: The molecular epidemiology of Mycobacterium bovis infections in Tanzania. Veterinary Microbiology 2006, I I 2(2-4):20I-2I 0.

13. Michel AL, Hlokwe TM, Coetzee ML, Mare L, Connoway L, Rutten VP, Kremer K: High Mycobacterium bovis genetic diversity in a low prevalence setting. Vet Microbiol 2008, I 26(I-3): I5I-I59.

14. Skuce RA, Brittain D, Hughes MS, Beck LA, Neill SD: Genomic fingerprinting of Mycobacterium bovis from cattle by restriction fragment length polymorphism analysis. J Clin Microbiol 1994, 32(10):2387-2392.

15. Kamerbeek J, Schouls L, Kolk A, van Agterveld M, van Soolingen D, Kuijper S, Bunschoten A, Molhuizen H, Shaw R, Goyal M, et al.: Simultaneous detection and strain differentiation of Mycobacterium tuberculosis for diagnosis and epidemiology. J Clin Microbiol 1997, 35(4):907-914.

16. Roring S, Hughes MS, Skuce RA, Neill SD: Simultaneous detection and strain differentiation of Mycobacterium bovis directly from bovine tissue specimens by spoligotyping. Vet Microbiol 2000, 74(3):227-236.

17. Cousins D, Williams S, Liebana E, Aranaz A, Bunschoten A, Van Embden J, Ellis T: Evaluation of four DNA typing techniques in epidemiological investigations of bovine tuberculosis. J Clin Microbiol 1998, 36(1):168-178.

18. Aranaz A, Liébena E, Mateos A, Dominguez L, Cousins D: Restriction fragment length polymorphism (RFLP) and Spacer oligonucleotide typing ("Spoligotyping"): a comparative analysis of fingerprinting strategies for Mycobacterium bovis. Journal of Vet Microbiology 1998, 6 I:3 II-324.

19. Van Soolingen D, de Haas PEW, Haagsma J, Eger T, Hermans PW, Ritacco MV, Alito A, van Embden JDA: Use of various genetic markers in differentiation of Mycobacterium bovis strains from animals and humans and for studying epidemiology of bovine tuberculosis. Journal of clinical Microbiology 1994, 32:2425-2433

20. Brudey K, Driscoll JR, Rigouts L, Prodinger WM, Gori A, Al-Hajoj SA, Allix C, Aristimuno L, Arora J, Baumanis V, et al:: Mycobacterium tuberculosis complex genetic diversity: mining the fourth international spoligotyping database (SpolDB4) for classification, population genetics and epidemiology. BMC Microbiol 2006, 6:23.

21. Oloya J, Kazwala R, Lund A, Opuda-Asibo J, Demelash B, Skjerve E, Johansen TB, Djonne B: Characterisation of mycobacteria isolated from slaughter cattle in pastoral regions of Uganda. BMC Microbiol 2007, 7:95.

22. Diguimbaye-Djaibe C, Hilty M, Ngandolo R, Mahamat HH, Pfyffer GE, Baggi F, Hewinson G, Tanner M, Zinsstag J, Schelling E: Mycobacterium bovis isolates from tuberculous lesions in Chadian zebu carcasses. Emerg Infect Dis 2006, I 2(5):769-77I.

23. Sahraoui N, Muller B, Guetarni D, Boulahbal F, Yala D, Ouzrout $R$, Berg S, Smith NH, Zinsstag J: Molecular characterization of Mycobacterium bovis strains isolated from cattle slaughtered at two abattoirs in Algeria. BMC Vet Res 2009, 5:4

24. Tortoli E, Cichero P, Piersimoni C, Simonetti MT, Gesu G, Nista D: Use of BACTEC MGIT 960 for recovery of mycobacteria from clinical specimens: multicenter study. | Clin Microbiol 1999, 37(II):3578-3582.

25. Hasegawa N, Miura T, Ishii K, Yamaguchi K, Lindner TH, Merritt $S$, Matthews JD, Siddiqi SH: New simple and rapid test for culture confirmation of Mycobacterium tuberculosis complex: a multicenter study. I Clin Microbiol 2002, 40(3):908-912.

26. Hasegawa N, Miura T, Ishizaka A, Yamaguchi K, Ishii K: Detection of mycobacteria in patients with pulmonary tuberculosis undergoing chemotherapy using MGIT and egg-based solid medium culture systems. Int J Tuberc Lung Dis 2002, 6(5):447-453.

27. Njanpop-Lafourcade BM, Inwald J, Ostyn A, Durand B, Hughes S, Thorel MF, Hewinson G, Haddad N: Molecular typing of Mycobacterium bovis isolates from Cameroon. J Clin Microbiol 200I, 39(I):222-227.
28. Hunter PR, Gaston MA: Numerical index of the discriminatory ability of typing systems: an application of Simpson's index of diversity. J Clin Microbiol 1988, 26(II):2465-2466.

29. Skuce RA, McCorry TP, McCarroll JF, Roring SM, Scott AN, Brittain D, Hughes SL, Hewinson RG, Neill SD: Discrimination of Mycobacterium tuberculosis complex bacteria using novel VNTRPCR targets. Microbiology 2002, I 48(Pt 2):519-528.

30. Duarte EL, Domingos M, Amado A, Botelho A: Spoligotype diversity of Mycobacterium bovis and Mycobacterium caprae animal isolates. Vet Microbiol 2008, I30(3-4):4I5-42I.

31. Aranaz A, Liebana E, Mateos A, Dominguez L, Vidal D, Domingo M, Gonzolez O, Rodriguez-Ferri EF, Bunschoten AE, Van Embden JD, et al:: Spacer oligonucleotide typing of Mycobacterium bovis strains from cattle and other animals: a tool for studying epidemiology of tuberculosis. I Clin Microbiol 1996, 34(I I):2734-2740.

32. Serraino A, Marchetti G, Sanguinetti V, Rossi MC, Zanoni RG, Catozzi L, Bandera A, Dini W, Mignone W, Franzetti F, et al.: Monitoring of transmission of tuberculosis between wild boars and cattle: genotypical analysis of strains by molecular epidemiology techniques. J Clin Microbiol I999, 37(9):2766-277I.

33. Stafford KJ: A review of diseases of parasites of the Kafue lechwe (Kobus leche kafuensis). J Wildl Dis 1991, 27(4):66I -667.

34. Corner LA: The role of wild animal populations in the epidemiology of tuberculosis in domestic animals: How to assess the risk. Veterinary Microbiology 2006, I I 2:303-3 I 2

35. Gracey JF, Collins DS, Huey RJ, eds: Meat Hygiene. 10th edition. W. B. Saunders \& ComponayToronto, London, NewYork; 1999.

36. Allix-Beguec C, Harmsen D, Weniger T, Supply P, Niemann S: Evaluation and strategy for use of MIRU-VNTRplus, a multifunctional database for online analysis of genotyping data and phylogenetic identification of Mycobacterium tuberculosis complex isolates. J Clin Microbiol 2008, 46(8):2692-2699.

Publish with Bio Med Central and every scientist can read your work free of charge

"BioMed Central will be the most significant development for disseminating the results of biomedical research in our lifetime. "

Sir Paul Nurse, Cancer Research UK

Your research papers will be:

- available free of charge to the entire biomedical community

- peer reviewed and published immediately upon acceptance

- cited in PubMed and archived on PubMed Central

- yours - you keep the copyright
BioMedcentral 